\title{
THORACIC EPIDURAL ANALGESIA FOR THE PREVENTION OF POST-ERCP PANCREATITIS: A RANDOMIZED STUDY OF 491 CASES
}

\section{Mikhail Turovets ${ }^{\bowtie} \mathbb{D}$, Alexander Popov (D), Viktor Mandrikov (D), Yuriy Vedenin (D), Andrej Ekstrem (1)}

Volgograd State Medical University, Volgograd, Russia

turovets_aro@mail.ru

ABSTRACT - AIM. To evaluate the effectiveness of thoracic epidural analgesia (TEA) for prevention of post-ERCP pancreatitis (PEP).

MATERIALS AND METHODS. Between 2015 and 2019, a randomized study of the results of endoscopic treatment in 491 patients was conducted. The first group of patients $(\mathrm{N}=247)$ received thoracic epidural analgesia during ERCP procedures, the patients of the second group $(\mathrm{N}=244)$ received a narcotic analgesic.

RESULTS. In the first (TEA) group there were no cases of pancreatic necrosis and fatal outcome, in the second (control) group in 7 (2.9\%) patients were diagnosed with this adverse event, of which $3(1.2 \%)$ patients died. A statistically significant reduction in the incidence of PEP was found due to the use of epidural analgesia in all age categories $(\mathrm{p}=$ $0.0004-0.0232)$, in women $(p=0.0000)$ and men $(p=0.0057)$, patients with jaundice $(\mathrm{p}=0.0000)$, with sphincter of Oddi dysfunction $(\mathrm{p}=0.0000)$, with common bile duct stones $(\mathrm{p}=$ $0.0004)$, with tumor $(p=0.0010)$, after biliary sphincterotomy $(\mathrm{p}=0.0000)$, biliary-stone extraction $(\mathrm{p}=0.0013)$, nasobiliary drainage $(\mathrm{p}=0.0016)$. The study has proved the effectiveness of thoracic epidural analgesia in patients with high risk of post-ERCP pancreatitis $(\mathrm{p}=0.0000)$. CONCLUSION. The use of thoracic epidural analgesia during therapeutic ERCP procedures is an effective method of preventing post-ERCP pancreatitis.

KEY W ORDS - therapeutic ERCP, prevention of post-ERCP pancreatitis, thoracic epidural analgesia.

\section{INTRODUCTION}

For more than 50 years ERCP procedures have been successfully used in the treatment of patients with benign and malignant diseases of hepatopancreatobiliary zone. Compared with surgery, endoscopic correction has significantly reduced the risk of adverse effects in a substantial number of patients with choledocholithiasis, sphincter of Oddi dysfunction, chronic calculous pancreatitis, tumors of the bile ducts and pancreas $[1,2,3]$.
The improvement of endoscopic techniques, specifically those of performing ERCP procedures, and the use of pharmacological prophylaxis have significantly reduced the risk of adverse effects. However, it still can't be claimed that ERCP procedures present a completely safe intervention. According to many authors, the greatest cause for concern is the post-ERCP pancreatitis (PEP) $[4,5,6,7]$. Numerous studies have shown that the PEP rate in the total sample reaches $10 \%$ and up to $40 \%$ in high risk patients $[8,9,10,11]$.

Since the moment ERCP procedures started to be used for treating patients the search for a universal and effective method of preventing PEP has been going on, but until now the problem has not been completely resolved $[12,13,14,15]$.

During the time we have been using ERCP procedures we have been actively implementing all available methods of PEP prevention, however the PEP rate has remained rather high. Based on his ample experience of using thoracic epidural analgesia (TEA) and the knowledge of its positive effects (good pain relief, increased perfusion in the area of regional block, the sphincter of Oddi relaxation), one of the authors of this article (M.I.T.) suggested applying it in therapeutic ERCP as a way to prevent PEP.

\section{MATERIALS AND METHODS}

A prospective controlled parallel randomized study has been conducted. Initially, we decided that a clinically significant result of applying TEA should be considered reducing of PEP incidence by $50 \%$.

The statistician of our clinic determined that to provide $80-90 \%$ of research power we needed a sample from two groups, comprising about 450-480 patients (used the Altman nomogram).

The study was approved by the Volgograd regional independent ethics committee (ref: 124/2007/12/24) and registered with ClinicalTrials. gov (NCT 01964066). All patients gave their written informed consent for participation in the study.

\section{Inclusion criteria:}

1. Patients with performed therapeutic ERCP;

2. The ERCP procedure was performed in a patient for the first time;

3. Prior to the ERCP procedure the patient didn't have any clinical signs of acute pancreatitis. 


\section{Exclusion criteria:}

Development of complications during the ERCP procedure that required urgent surgical intervention (massive haemorrhage, Dormia basket avulsion and others).

Between January 2015 and December 2019 786 ERCP procedures were conducted. All the patients were hospitalized. In $53(6.7 \%)$ patients had endoscopic intervention carried out for diagnostic purposes. In 528 (67.2\%) cases, the intervention was performed for the first time; in 205 (26.1\%) cases the patients already had ERCP procedures performed before. 27 of 528 (5.1\%) patients were diagnosed with symptoms of acute pancreatitis before the intervention. One patient refused to participate in the experiment.

Preoperatively the subjects were randomly assigned (by using sealed envelopes — blind randomization) into two groups, 250 patients each.

The patients of the first group had TEA applied during the ERCP procedure; other methods of pain relief were applied to the patients of the second (control) group.

The first group (TEA group) of patients received the following premedication: atropine sulfate $0.5-1 \mathrm{mg}$, midazolamum $5 \mathrm{mg}$. Puncture and catheterization of the epidural space was carried out in accordance with the standard procedure at the level of ThVII-ThVIII vertebrae. Half an hour before performing ERCP ropivacainum $0.5 \%-8-10 \mathrm{ml}$ was injected into the epidural space.

The second group (control group) of patients received the following premedication: atropine sulfate 0.5-1 mg, midazolamum $5 \mathrm{mg}$, trimeperidinum $2 \%$ $-1 \mathrm{ml}$.

General anaesthesia with propofol $2 \mathrm{mg} / \mathrm{kg}$ with or without orotracheal intubation with a cuffed tube was used for high-risk patients considering their clinical status (i.e., age, patients with extremely poor health status (American Society of Anaesthesiologists (ASA IV)), prussic dementia and clinical presentation).

In the TEA group three patients were excluded from the experiment due to unsuccessful attempt to epidural catheterization (2 cases) and retroduodenal perforation (1 case). Six patients were excluded from the second group on account of massive haemorrhage ( 1 case), retroduodenal perforation ( 2 cases), Dormia basket avulsion ( 1 case), failed cannulation ( 2 cases), which required surgical intervention.

Ultimately, the treatment outcomes of 491 patients were analyzed: 247 patients in the first /TEA group and 244 patients in the second/control group.

After receiving ERCP procedures all the patients were admitted to the intensive care unit. The TEA group patients continued to receive epidural analgesia (ropivacainum $0.2 \%-5 \mathrm{ml} / \mathrm{h}$ ). The control group patients received non-narcotic analgesics (Ketorolacum 3\%-1 ml). All the patients from both groups received infusion therapy (crystalloids $10-15 \mathrm{ml} / \mathrm{kg}$ ).

The variables documented for each case included the characteristics of the patients and the specifics of each procedure, as listed in Table 1. During the next day rounds at least three surgeons, who did not participate in the study, diagnosed the presence or absence of acute pancreatitis. Acute pancreatitis was diagnosed on the basis of the clinical picture (characteristic abdominal pain, nausea, vomiting, gastric stasis, tachycardia, etc.), laboratory data (hyperamylasemia, leukocytosis) and ultrasonoscopy results. The sphincter of Oddi dysfunction (SOD) was signaled by the common bile duct extension (more than $8 \mathrm{~mm}$ ) in the absence of stones and tumors of the common bile duct or pancreas and/or difficult cannulation of choledochitis (more than 5 attempts). Biliary and/or pancreatic sphincter manometry was not used due to lack of equipment.

Procedural complexity was rated by an established grading scale. Grade 1 includes all standard biliary procedures; grade 2 includes large bile-duct stones extraction, hilar strictures and benign biliary strictures. The variables (demographic data, the nature of the disease, the results of laboratory and instrumental studies, the outcome, etc.) were introduced into researcher's database within 10 days after the intervention. Unfortunately, the public database of our clinic is only being generated at the moment.

Demographic characteristics of the patients are presented in Table 1 . The average age of the patients in the study group was $58 \pm 1.0$ years, in the control group $-62 \pm 1.0$ years. The number of women and younger patients (under 65) was slightly larger in the TEA group: $66.0 \%$ vs $64.8 \%$ and $64.8 \%$ vs $53.7 \%$, respectively. The study groups differed in some other variables. Patients with tumors $(33.2 \%$ vs $36.5 \%$, $\mathrm{p}=0.4460)$ and jaundice (33.2\% vs $38.1 \%, \mathrm{p}=0.2554)$ were slightly larger in the TEA group. At the same time, in the TEA group we more frequently observed patients with common bile duct stones $(50.6 \%$ vs $42.2 \%, \mathrm{p}=0.0622)$, SOD ( $15.0 \%$ vs $9.0 \%, \mathrm{p}=0.0522)$, common bile duct stones and SOD (14.2\% vs $9.0 \%$, $\mathrm{p}=0.0747)$, calculous cholecystitis ( $30.8 \%$ vs $29.5 \%$, $\mathrm{p}=0.7608$ ). Since the TEA group was presented by younger patients, concomitant diseases were detected in $74.5 \%(184 / 247)$ patients in the TEA group and in $84.4 \%(206 / 244)$ patients in the control group $(p=0.0065)$. However, the number of patients with severe comorbidities (ASA IV) did not differ between the study groups $(\mathrm{p}=0.2573)$; the majority of such patients were diagnosed with cardiovascular dis- 
eases $(73.9 \%$ [136/184] in the first group and $74.8 \%$ [154/206] in the second group). Other variables did not differ between the study groups.

To determine the statistical significance of differences between the study groups were used nonparametric tests. Each group was divided into subgroups differed by age, sex, nature of the disease and character of the intervention. The statistical processing was performed using the Mann-Whitney U-test and $\chi^{2}$ Pearson. The difference was considered significant at the significance level of more than $95 \%(\mathrm{p}<0.05)$. Analyses were performed with Statistica 10.0 (StatSoft Inc., USA).

\section{RESULTS AND DISCUSSION}

A total of 491 therapeutic ERCP procedures were performed and documented over the period of 5 years. Depending on the nature of the disease different types of endoscopic procedures were used. The study groups somewhat differed on this indicator. In the TEA group the procedures of biliary sphincterotomy (79.4\% vs $77.9 \%, \mathrm{p}=0.6886)$, balloon dilation $(20.2 \%$ vs $18.0 \%, \mathrm{p}=0.5337)$, biliary-stone extraction $(57.5 \%$ vs $52.5 \%, \mathrm{p}=0.2626)$ and lithotripsy $(11.3 \%$ vs $9.4 \%$, $\mathrm{p}=0.4880$ ) were performed slightly more often. In the second group, was statistically insignificantly more often performed was biliary-stent insertion $(27.9 \%$ vs $23.1 \%, p=0.2230$ ). For the prevention of PEP in $15.8 \%$ of patients of the TEA group and $12.3 \%$ in the second group pancreatic stents $(\mathrm{p}=0.2653)$ were installed. The study groups did not differ in the procedural complexity (Table 1).

During the time of this study $46(9.4 \%[46 / 491])$ cases of PEP were diagnosed in total; $89.1 \%(41 / 46)$ of total PEP cases were registered in the second group (Table 2). Thus, the incidence of PEP in the TEA group was 2.0\% (5/247) while in the control group it was $16.8 \%(41 / 244)(\mathrm{p}=0.0000)$.

The absolute majority of PEP patients in both groups had a mild form of disease (80\% [4/5] and 66\% $[27 / 41]$ observations, respectively) and we were able to arrest their clinical manifestations within three days. One patient (20\%) from the TEA group, and 7 (17\%) patients from the second group needed the continuation of intensive anti-pancreatic therapy up to 7 days. Taking into account the clinical picture and data from laboratory and instrumental tests $7(2.9 \%[7 / 244])$ patients in the control group were diagnosed with pancreatic necrosis. In all cases the symptoms of pancreatic necrosis developed rapidly and were characterized by total and subtotal lesion of the pancreas. $42.9 \%$ (3/7) of patients with pancreatic necrosis had an unfavorable outcome: two patients died from multiple organ failure syndrome and one patient from acute coronary syndrome.
Clinical and procedural predictors of PEP are shown in Table 3 .

A statistically significant reduction in the incidence of PEP was found due to the use of epidural analgesia in all age categories $(\mathrm{p}=0.0004-0.0232)$, in women $(\mathrm{p}=0.0000)$ and men $(\mathrm{p}=0.0057)$, patients with jaundice $(p=0.0000)$, with sphincter of Oddi dysfunction $(p=0.0000)$, with common bile duct stones $(p=0.0004)$, with tumor $(p=0.0010)$, after biliary sphincterotomy $(p=0.0000)$, biliary-stone extraction $(\mathrm{p}=0.0013)$, naso-biliary drainage $(\mathrm{p}=0.0016)$. Among the patients of the TEA group over 65, with tumors, with calculous pancreatitis with severe comorbidities (ASA III-IV), after the installation of biliary stents and lithotripsy there was not a single case of developing PEP. There was not a single death case in the TEA group. More frequently the postoperative period was accompanied by the development of PEP in women $(10.3 \%$ [35/341]), younger patients (under 65) $(10.3 \%[30 / 292])$ and in patients with SOD $(18.1 \%$ [21/116]). According to our data, these factors increased the risk of developing PEP. The patients who had a combination of these factors were considered at high risk for PEP.

Table 4 presents the data on the incidence of PEP in patients at high risk of developing this undesirable consequence.

During the entire time of using ERCP procedures we searched for methods of preventing the development of PEP. We conducted numerous investigations aimed at studying the preventive effect of different groups of medications (indomethacin, somatostatin, heparin, etc.) $[16,17]$. For this purpose we proposed to use various tactics of endoscopic intervetions [18]. Nevertheless the development of PEP remained a major problem after therapeutic ERCP procedures [19].

The study has provided reliable data on the efficacy of applying TEA in therapeutic ERCP procedures in order to prevent the development of PEP. The study has demonstrated that the incidence of PEP was reduced from $16.8 \%$ to $2.0 \%$ of cases. In the TEA group all the PEP cases were of mild to moderate severity. The use of TEA helps to prevent the development of pancreatic necrosis and unfavourable outcome, which greatly increases the safety of applying therapeutic ERCP procedures to patients at high risk for PEP and severe comorbidities. Besides it is important to mention that the endoscopists noted that the use of TEA creates a more comfortable environment for their work.

No doubt this prevention method has its drawbacks. The main disadvantages, we believe, are the following: the necessity to engage a doctor who has mastered the technique of performing TEA; the 
Table 1. Selected subject and procedural characteristics of patients

\begin{tabular}{|c|c|c|c|}
\hline \multirow{2}{*}{ Variable } & \multicolumn{2}{|l|}{ Total (\% of total) } & \multirow{2}{*}{$p$} \\
\hline & TEA group $(\mathrm{N}=247)$ & Control group $(\mathrm{N}=244)$ & \\
\hline \multicolumn{4}{|l|}{ Subject } \\
\hline \multicolumn{4}{|l|}{ Age } \\
\hline $18-50 y$ & $67(27.1)$ & $48(19.7)$ & 0.0512 \\
\hline $51-65 y$ & $93(37.7)$ & $83(34.0)$ & 0.4010 \\
\hline $66-80 y$ & $66(26.7)$ & $90(36.9)$ & $0.0156^{*}$ \\
\hline$>80 y$ & $21(8.5)$ & $23(9.4)$ & 0.7200 \\
\hline \multicolumn{4}{|l|}{ Sex } \\
\hline Women & $163(66.0)$ & $158(64.8)$ & 0.7732 \\
\hline \multicolumn{4}{|l|}{ Context } \\
\hline Jaundice & $82(33.2)$ & $93(38.1)$ & 0.2554 \\
\hline Common bile duct stones & $125(50.6)$ & $103(42.2)$ & 0.0622 \\
\hline SOD & $37(15.0)$ & $22(9.0)$ & 0.0522 \\
\hline Common bile duct stones and SOD & $35(14.2)$ & $22(9.0)$ & 0.0747 \\
\hline Tumor & $82(33.2)$ & $89(36.5)$ & 0.4460 \\
\hline Calculous pancreatitis & $8(3.2)$ & $8(3.3)$ & 0.9802 \\
\hline Prior cholecystectomy & $81(32.8)$ & $75(30.7)$ & 0.6247 \\
\hline Calculous cholecystitis & $76(30.8)$ & $72(29.5)$ & 0.7608 \\
\hline \multicolumn{4}{|l|}{ ASA grade } \\
\hline IV & $13(5.3)$ & $19(7.8)$ & 0.2573 \\
\hline III & $41(16.6)$ & $40(16.4)$ & 0.9510 \\
\hline I and II & $193(78.1)$ & $185(75.8)$ & 0.5418 \\
\hline \multicolumn{4}{|l|}{ Procedural } \\
\hline Biliary sphincterotomy & $196(79.4)$ & $190(77.9)$ & 0.6886 \\
\hline Balloon dilation & $50(20.2)$ & $44(18.0)$ & 0.5337 \\
\hline Biliary-stone extraction & $142(57.5)$ & $128(52.5)$ & 0.2626 \\
\hline Installation of biliary stent & $57(23.1)$ & $68(27.9)$ & 0.2230 \\
\hline Lithotripsy & $28(11.3)$ & $23(9.4)$ & 0.4880 \\
\hline Installation of pancreatic stent & $39(15.8)$ & $30(12.3)$ & 0.2653 \\
\hline Naso-biliary drainage & $47(19.0)$ & $54(22.1)$ & 0.3951 \\
\hline \multicolumn{4}{|l|}{ Difficulty gradew } \\
\hline 2 & $83(33.6)$ & $72(29.5)$ & \multirow{2}{*}{0.3290} \\
\hline 1 & $164(66.4)$ & $172(70.5)$ & \\
\hline
\end{tabular}

Note: ${ }^{*} P<0.05$, statistically significant; ASA - American Society of Anaesthesiologists; SOD - sphincter of Oddi dysfunction.

Table 2. Post-ERCP pancreatitis and severity

\begin{tabular}{|c|c|c|c|c|}
\hline \multirow{2}{*}{ Group } & \multirow{2}{*}{ Total (\% of total procedures) } & \multicolumn{2}{|c|}{ Severity (\% of post-ERCP pancreatitis) } & \multirow{2}{*}{$\begin{array}{l}\text { Mortality (\% of total } \\
\text { procedures) }\end{array}$} \\
\hline & & Mild/Moderate & Severe & \\
\hline TEA group $(\mathrm{N}=247)$ & $5(2.0)$ & $5(100)$ & $0(0)$ & $0(0)$ \\
\hline $\begin{array}{l}\text { Control group }(\mathrm{N}= \\
244)\end{array}$ & $41(16.8)$ & $34(82.9)$ & $7(17.1)$ & $3(1.2)$ \\
\hline $\mathrm{p}$ & $0.0000^{*}$ & $0.0000^{*}$ & $0.0073^{*}$ & 0.0805 \\
\hline
\end{tabular}

Note: ${ }^{*} P<0.05$, statistically significant. 
Table 3. Clinical and procedural predictors of post-ERCP pancreatitis

\begin{tabular}{|c|c|c|c|}
\hline \multirow{2}{*}{ Variable } & \multicolumn{2}{|c|}{ post-ERCP pancreatitis/total (\% total of variable) } & \multirow{2}{*}{$p$} \\
\hline & TEA group & Control group & \\
\hline \multicolumn{4}{|l|}{ Clinical } \\
\hline \multicolumn{4}{|l|}{ Age } \\
\hline $18-50 y$ & $2 / 67(3.0)$ & $12 / 48(25.0)$ & $0.0004^{*}$ \\
\hline $51-65 y$ & $3 / 93(3.2)$ & $13 / 83(15.7)$ & $0.0042^{*}$ \\
\hline $66-80 y$ & $0 / 66(0)$ & $11 / 90(12.2)$ & $0.0032^{*}$ \\
\hline$>80 y$ & $0 / 21(0)$ & $5 / 23(21.7)$ & $0.0232^{*}$ \\
\hline \multicolumn{4}{|l|}{ Sex } \\
\hline Women & $4 / 163(2.5)$ & $31 / 158(19.6)$ & $0.0000^{*}$ \\
\hline Men & $1 / 84(1.2)$ & 10/86 (11.6) & $0.0057^{*}$ \\
\hline \multicolumn{4}{|l|}{ Context } \\
\hline Jaundice & $1 / 82(1.2)$ & $20 / 93(21.5)$ & $0.0000^{*}$ \\
\hline Common bile duct stones & $1 / 125(0.8)$ & 12/103 (11.7) & $0.0004^{*}$ \\
\hline SOD & $1 / 37(2.7)$ & $13 / 22(59.1)$ & $0.0000^{*}$ \\
\hline Common bile duct stones and SOD & $3 / 35(8.6)$ & $4 / 22(18.2)$ & 0.2818 \\
\hline Tumor & $0 / 82(0)$ & $11 / 89(12.4)$ & $0.0010^{*}$ \\
\hline Calculous pancreatitis & $0 / 8(0)$ & $1 / 8(12.5)$ & 0.3017 \\
\hline Prior cholecystectomy & $4 / 81(4.9)$ & $11 / 75(14.7)$ & $0.0395^{*}$ \\
\hline Calculous cholecystitis & $1 / 76(1.3)$ & $18 / 72(25.0)$ & $0.0000^{*}$ \\
\hline \multicolumn{4}{|l|}{ ASA grade } \\
\hline IV & $0 / 13(0)$ & $1 / 19(5.7)$ & 0.4007 \\
\hline III & $0 / 41(0)$ & $4 / 40(10.0)$ & $0.0378^{*}$ \\
\hline I and II & $5 / 193(2.6)$ & $36 / 185(19.5)$ & $0.0000^{*}$ \\
\hline \multicolumn{4}{|l|}{ Procedural } \\
\hline Biliary sphincterotomy & 3/196 (1.5) & $32 / 190(16.8)$ & $0.0000^{*}$ \\
\hline Balloon dilation & $3 / 50(6.0)$ & $5 / 44(11.4)$ & 0.3524 \\
\hline Biliary-stone extraction & $4 / 142(2.8)$ & $17 / 128(13.3)$ & $0.0013^{*}$ \\
\hline Installation of biliary stent & $0 / 57(0)$ & 9/68 (13.2) & $0.0044^{*}$ \\
\hline Lithotripsy & $0 / 28(0)$ & $3 / 23(13.0)$ & $0.0489^{*}$ \\
\hline Installation of pancreatic stent & $0 / 39(0)$ & $3 / 30(10.0)$ & $0.0435^{*}$ \\
\hline Naso-biliary drainage & $2 / 47(4.3)$ & $15 / 54(27.8)$ & $0.0016^{*}$ \\
\hline
\end{tabular}

Note: ${ }^{*} P<0.05$, statistically significant.

Table 4. Post-ERCP pancreatitis incidence in high-risk patients

\begin{tabular}{l|l|l|l|l}
\hline \multirow{2}{*}{ Group } & Total (post-ERCP pancreatitis) & Severity (\% of total) & & \\
\cline { 3 - 5 } & & Mild & Moderate & Severe \\
\hline TEA group $(\mathrm{N}=46)$ & $46(4)$ & $3(6.5)$ & $1(2.2)$ & $0(0.0)$ \\
\hline Control group $(\mathrm{N}=24)$ & $24(13)$ & $7(29.2)$ & $4(16.7)$ & $2(8.3)$ \\
\hline $\mathrm{p}$ & $0.0000^{*}$ & $0.0003^{*}$ & & $0.0470^{*}$ \\
\hline
\end{tabular}

Note: ${ }^{*} P<0.05$, statistically significant. 
invasiveness of the method (despite its safety); its limited application for patients with coagulopathies (e.g. patients with liver failure); its use limited only to hospitalized patients. There remain some unresolved issues. Not all patients undergoing therapeutic ERCP procedures are in need of TEA. Currently neither indications nor contraindications for using this method of preventing PEP have been identified. The need for TEA while performing general anaesthesia also remains unclear. These issues need to be addressed in further research.

The fact that the study included all patients meeting of the inclusion criteria, hospitalized in clinic for the last 5 years, and the sample size indicates the validity of the study.

\section{CONCLUSION}

The use of thoracic epidural analgesia significantly reduces the incidence of post-ERCP pancreatitis in therapeutic ERCP procedures. The use of TEA during therapeutic ERCP procedures is an effective prevention method for patients at high risk of post-ERCP pancreatitis. In conclusion we would like to note that this study does not call into question the effectiveness of other prevention methods recommended by various authors, but rather complements them. As always, each patient requires an individual approach.

The authors state that they have no conflict of interests.

Contributors

MIT and VVM collected, analyzed, and interpreted data and made the figures. ASP did the literature review and collected data. AVE and YuIV collected data and made the figures. MIT and VVM interpreted and analysed the data. MIT, ASP, AVE, YuIV and VVM prepared the manuscript for submission.

\section{REFERENCES}

1. Tryliskyy Y., Bryce G.J. Post-ERCP pancreatitis: Pathophysiology, early identification and risk stratification. Adv Clin Exp Med. 2018; 27(1): 149-154. doi: $10.17219 /$ acem $/ 66773$

2. Mine T., Morizane T., Kawaguchi Y., Akashi R., HANAdA K. ET AL. Clinical practice guideline for post-ERCP pancreatitis. J Gastroenterol. 2017; $52(9)$ : 1013-1022. doi: 10.1007/s00535-017-1359-5

3. Parekh P.J., Majithia R., Sikka S.K., Baron T.H. The "Scope" of Post-ERCP Pancreatitis. Mayo Clin Proc. 2017; 92(3): 434-448. doi: 10.1016/j.mayocp.2016.10.028

4. Patai A., Solymosi N., Mohácsi L., Patai A.V. Indomethacin and diclofenac in the prevention of
post-ERCP pancreatitis: a systematic review and metaanalysis of prospective controlled trials. Gastrointest Endosc. 2017; 85(6): 1144-1156.e1. doi: 10.1016/j. gie.2017.01.033

5. SiIKI A., LaUkKarinen J. Can we prevent postERCP pancreatitis? Duodecim. 2017; 133(3): 267-74.

6. Lin Y., LiU X., CaO D.Q., TANG J.H. eT AL. Analysis of risk factors and prevention strategies of post-ERCP pancreatitis. Eur Rev Med Pharmacol Sci. 2017; 21(22): 5185-5190. doi: 10.26355/eurrev_201711_13838

7. Garg R., Mohan B.P., Krishnamoorthi R., Rustagi T. Pre-endoscopic retrograde cholangiopancreatography (ERCP) administration of rectal indomethacin in unselected patients to reduce postERCP pancreatitis: A systematic review and metaanalysis. Indian J Gastroenterol. 2018; 37(2): 120-126. doi: $10.1007 /$ s12664-018-0841-1

8. Kang X., Zheng L., Zeng W., Yang S., Sun H. ET AL. Risk Factors for Post-ERCP Pancreatitis in High-Risk Patients Receiving Post-procedure Rectal Indomethacin. J Gastrointest Surg. 2018; 22(11): 1903-1910. doi: 10.1007/s11605-018-3864-0

9. Wu D., Wan J., Xia L., Chen J., Zhu Y., Lu N. The Efficiency of Aggressive Hydration With Lactated Ringer Solution for the Prevention of Post-ERCP Pancreatitis: A Systematic Review and Meta-analysis. J Clin Gastroenterol. 2017; 51(8): e68-e76. doi: 10.1097/MCG.0000000000000856

10. Tse F., Yuan Y., Moayyedi P., LeOntiadis G.I., BARKun A.N. Double-guidewire technique in difficult biliary cannulation for the prevention of post-ERCP pancreatitis: a systematic review and meta-analysis. Endoscopy. 2017; 49 (1): 15-26. doi: 10.1055/s-0042119035

11. Huang Q., Shao F., Wang C., Qi W., Qiu L.J., LIU Z. Nasobiliary drainage can reduce the incidence of post-ERCP pancreatitis after papillary large balloon dilation plus endoscopic biliary sphincterotomy: a randomized controlled trial. Scand J Gastroenterol. 2018; 53(1): 114-119. doi: $10.1080 / 00365521.2017 .1391329$

12. LeVENICK J.M., Gordon S.R., FAdDEN L.L., LEVY L.C., ROCKACY M.J. ET AL. Rectal Indomethacin Does Not Prevent Post-ERCP Pancreatitis in Consecutive Patients. Gastroenterology. 2016; 150(4): 911-7. doi: $10.1053 /$ j.gastro.2015.12.040

13. Ding X., Zhang F., WANg Y. Risk factors for postERCP pancreatitis: A systematic review and metaanalysis. Surgeon. 2015; 13(4): 218-29. doi: 10.1016/j. surge.2014.11.005

14. Hwang H.J., Guidi M.A., Curvale C., lasa J., Matano R. Post-ERCP pancreatitis: early precut or pancreatic duct stent? A multicenter, randomizedcontrolled trial and cost-effectiveness analysis. Rev Esp Enferm Dig. 2017; 109(3): 174-179. doi: 10.17235/ reed.2017.4565/2016 
15. Smeets X.J., da Costa D.W., Besselink M.G., BRUNO M.J., FoCKeNS P. ET AL. Systematic review: periprocedural hydration in the prevention of postERCP pancreatitis. Aliment Pharmacol Ther. 2016; 44(6): 541-53. doi: 10.1111/apt.13744

16. Zhao Z.H., Hu L.H., ReN H.B., Zhao A.J., QIAN Y.Y. ET AL. Incidence and risk factors for post-ERCP pancreatitis in chronic pancreatitis. Gastrointest Endosc. 2017; 86(3): 519-524.e1. doi: 10.1016/j. gie.2016.12.020

17. Leerhoy B., Elmunzer B.J. How to Avoid PostEndoscopic Retrograde Cholangiopancreatography
Pancreatitis. Gastrointest Endosc Clin N Am. 2018; 28(4): 439-454. doi: 10.1016/j.giec.2018.05.007

18. Yokoe M., Takada T., Mayumi T., Yoshida M., IsAJI S. ET AL. Japanese guidelines for the management of acute pancreatitis: Japanese Guidelines 2015. J Hepatobiliary Pancreat Sci. 2015; 22(6): 405-32. doi: 10.1002/jhbp.259

19. Zhang C., Yang Y.L., Ma Y.F., Zhang H.W., LI J.Y. ET AL. The modified pancreatic stent system for prevention of post-ERCP pancreatitis: a case-control study. BMC Gastroenterol. 2017; 17(1): 108. doi: $10.1186 /$ s12876-017-0661-2 